\title{
Exploring the effects of the rural built environment on household car ownership after controlling for preference and attitude
}

Citation for published version (APA):

Ao, Y., Yang, D., Chen, C., \& Wang, Y. (2019). Exploring the effects of the rural built environment on household car ownership after controlling for preference and attitude: Evidence from Sichuan, China. Journal of Transport Geography, 74, 24-36. https://doi.org/10.1016/j.jtrangeo.2018.11.002

\section{Document license:}

TAVERNE

DOI:

10.1016/j.jtrangeo.2018.11.002

Document status and date:

Published: 01/01/2019

\section{Document Version:}

Publisher's PDF, also known as Version of Record (includes final page, issue and volume numbers)

\section{Please check the document version of this publication:}

- A submitted manuscript is the version of the article upon submission and before peer-review. There can be important differences between the submitted version and the official published version of record. People interested in the research are advised to contact the author for the final version of the publication, or visit the $\mathrm{DOI}$ to the publisher's website.

- The final author version and the galley proof are versions of the publication after peer review.

- The final published version features the final layout of the paper including the volume, issue and page numbers.

Link to publication

\footnotetext{
General rights

- You may freely distribute the URL identifying the publication in the public portal. follow below link for the End User Agreement:

www.tue.nl/taverne

Take down policy

If you believe that this document breaches copyright please contact us at:

openaccess@tue.nl

providing details and we will investigate your claim.
}

Copyright and moral rights for the publications made accessible in the public portal are retained by the authors and/or other copyright owners and it is a condition of accessing publications that users recognise and abide by the legal requirements associated with these rights.

- Users may download and print one copy of any publication from the public portal for the purpose of private study or research.

- You may not further distribute the material or use it for any profit-making activity or commercial gain

If the publication is distributed under the terms of Article 25fa of the Dutch Copyright Act, indicated by the "Taverne" license above, please 


\title{
Exploring the effects of the rural built environment on household car ownership after controlling for preference and attitude: Evidence from Sichuan, China
}

\author{
Yibin Ao ${ }^{\mathrm{a}, \mathrm{b}}$, Dujuan Yang ${ }^{\mathrm{c}}$, Chuan Chen ${ }^{\mathrm{b}, *}$, Yan Wang ${ }^{\mathrm{d}}$ \\ ${ }^{a}$ College of Environment and Civil Engineering, Chengdu University of Technology, Chengdu, Sichuan 610059, China \\ ${ }^{\mathrm{b}}$ Business School, Sichuan University, Chengdu, Sichuan 610065, China \\ ${ }^{\mathrm{c}}$ Information Systems of the Built Environment, Department of the Built Environment, Eindhoven University of Technology, P.O. Box 513, Eindhoven 5600, the Netherlands \\ ${ }^{\mathrm{d}}$ Department of Engineering Management, Sichuan College of Architectural Technology, Deyang, Sichuan 618000, China
}

\section{A R T I C L E I N F O}

\section{Keywords:}

Car ownership

Rural built environment

Preference and attitude

Multinomial logit model

Exploratory factor analysis

Rural China

\begin{abstract}
A B S T R A C T
With the rapid infrastructure development and economic growth in China, household car ownership in the country's rural areas has changed dramatically in the past 16 years. The total number of cars owned by households in rural areas is currently 12 times higher than it was 16 years ago. The exploration of the effects of the built environment on household car ownership in China's rural areas is worthwhile. However, few studies have investigated this topic. To fill in the research gap, this work collected 374 household data from rural areas in China to examine the effects of the built environment in Sichuan's rural areas on the number of cars in a household. It considered family structure, socioeconomic characteristics, and individual's perceptions of the built environment, preferences towards the built environment and attitudes towards car ownership (shortened to perceptions, preferences and attitudes from now on). Geographic information system (GIS) technology, combined with on-site measurement, was used for data collection. The multinomial logit model was applied for estimation. Household structure and the built environment (including the perceived built environment and the objective built environment) significantly influence the number of cars in a household. By contrast, preference and attitude attributes have less influence on car ownership. Most of the findings are in line with the literature in the context of Chinese cities. Nevertheless, new results are also found. For example, rural hukou, and building density have significant positive impacts on household car ownership in China's rural areas, which is in contrast with their effects on cities. As the first study on rural areas in China, this research provides some insights for rural planners and policymakers to understand better the relationship between built environment and household car ownership.
\end{abstract}

\section{Introduction}

China, as the most populous country in the world, is undergoing rapid economic and infrastructure development. With the accelerated road construction and economic growth, the need for cars is increasing in China (Belgiawan et al., 2014; Jiang et al., 2017; Pucher et al., 2007). In the past decade, the number of cars per household and the kilometers traveled by cars have exhibited a rapid growth trend. The total number of owned private vehicles reached 163,302,200 by the end of 2016, which was 26.15 times that of 2000 (National Bureau of Statistics, 2017). Moreover, the average distance traveled has increased dramatically. For example, the average distance traveled by private vehicles in Beijing exceeded 15,000 km/year in 2010 (Li and Zhao, 2017). The rapid increase in the number of cars and traveled kilometers leads to high energy consumption, air pollution, traffic congestion, and obesity (Handy et al., 2005; Li and Zhao, 2017; Potoglou and Kanaroglou, 2008). It has caused various problems, such as photochemical smog pollution, in China (Li and Zhao, 2017; Protection, 2016). The annual growth rate of fossil fuel demand in the transportation sector has reached $10.56 \%$ (Wang et al., 2011). A slight increase in car ownership per capita will cause a huge increase in energy consumption and carbon dioxide emissions considering the large population of China. Therefore, the importance of research on car ownership has become increasingly prominent (Aditjandra et al., 2016; Buehler et al., 2017; Li and Zhao, 2017). A growing number of researchers have begun to study car ownership in the context of China or Asia (Belgiawan et al., 2014; Ding

\footnotetext{
* Corresponding author.

E-mail address: chuanc2012@126.com (C. Chen).
} 


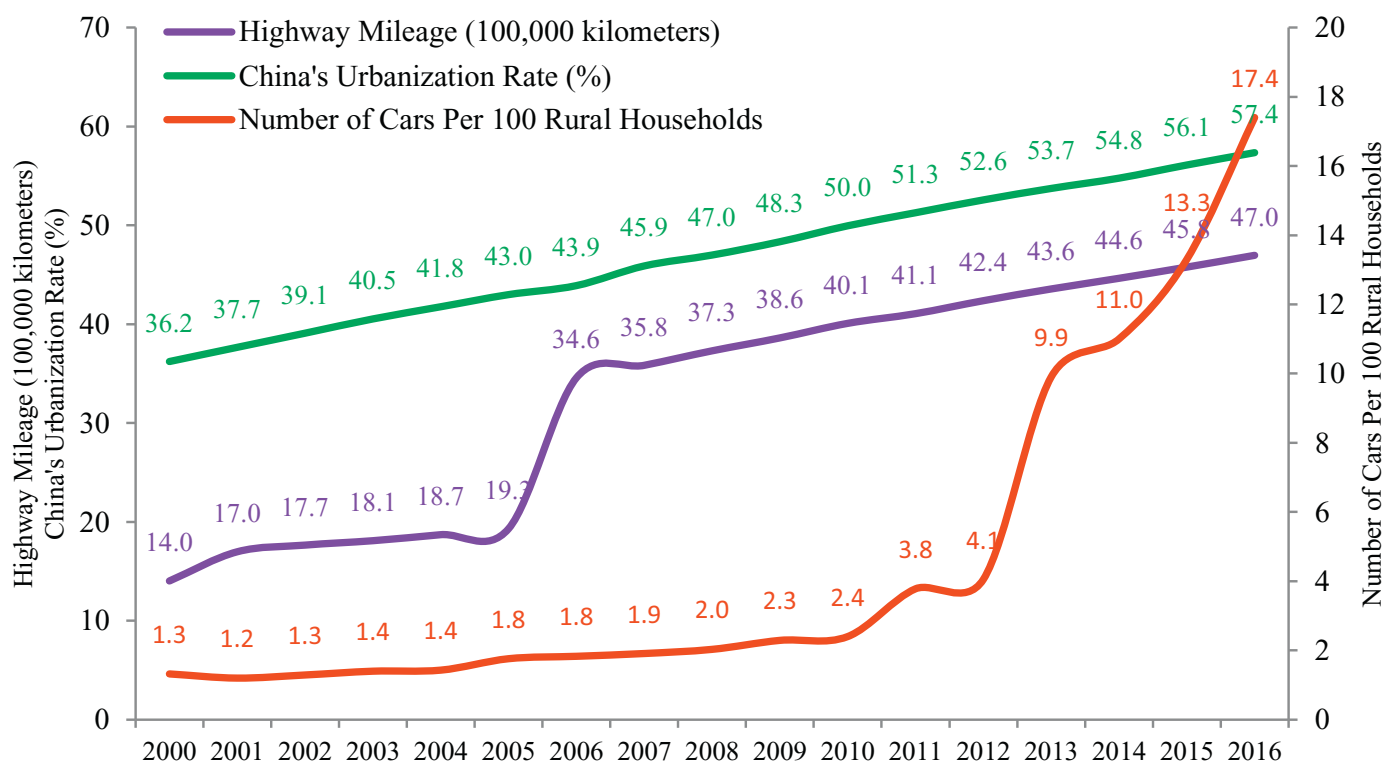

Fig. 1. Urbanization Rate, Highway Mileage and Car Ownership of Rural China. Sources: China Statistical Yearbook (2001-2017).

et al., 2017b; Yang et al., 2017; Pan et al., 2009; Pucher et al., 2007; Yang, 2010). However, they have mainly focused on metropolises, such as Beijing, Shanghai, Shenzhen, Nanjing, and Guangzhou (Wang and Zhou, 2017). A massive infrastructure investment has recently occurred in rural areas. By the end of 2016, the mileage of China's highway routes reached 4,696,263 km, which was 3.35 times that in 2000 . In 2016, the fixed-asset investment of rural households was 3.43 times that in 2000 , while the disposable income of rural residents was 5.49 times that in 2000 (National Bureau of Statistics, 1986-2017). Moreover, the number of cars per 100 households was 17.4 , which was 13.18 times that in 2000 (National Bureau of Statistics, 1986-2017) (Fig. 1). In particular, the number of cars per 100 rural households has increased rapidly in the past 5 years, considering that China has a rural population of nearly $50 \%$. Therefore, the study on car ownership and its influencing factors in rural China is of utmost significance for achieving energy conservation and emission reduction in transportation. To the best of our knowledge, however, few studies have focused on car ownership in China's rural areas.

This study aims to fill in the aforementioned research gap by exploring the relationship between the built environment and household car ownership using geographic information and survey data from 374 households in rural Sichuan, China. The multinomial logit (MNL) model was applied. It also takes account for socio-demographic factors and individual's preference and attitude in the context of rapid urbanization and new construction in rural Sichuan. Moreover, a comparison of effects between the perceived built environment, and the objective built environment on the car ownership of rural households was conducted.

The remainder of this paper is organized as follows. Section 2 discusses the existing literature about household car ownership. Section 3 presents the methodology used in the study. The data collection method, variable specification, and model specification are described in Section 4. The model results are discussed in Section 5. Finally, Section 6 concludes the paper by providing the key findings of the study and policy recommendations.

\section{Literature review}

Car ownership is an important intermediate factor in the study of the built environment and travel behavior (Cao et al., 2007). In the past few decades, a large number of studies in Western developed countries have used empirical data and various research methods to explore the relationships among the built environment, car ownership, and travel behavior (Jiang et al., 2017). The built environment, individual's preference and attitude, and socio-demographic factors are the three main factors that influence household car ownership based on the existing literature (Cao et al., 2009; Handy et al., 2005; Salon, 2015).

\subsection{Built environment}

The built environment has been widely accepted as $6 \mathrm{D}$, including density, diversity, design, destination accessibility, distance to transit, and demand management (Ewing and Cervero, 2001, 2010; Ewing and Handy, 2009; Ewing et al., 2015; Vance and Hedel, 2007). Numerous studies have demonstrated that there is a significant relationship between the built environment and car ownership. The reasonable design could reduce travel energy consumption. In particular, there is a significant negative effect of the built environment density on household car ownership. People are less likely to have a car or have fewer cars if they are living in a high density built environment (Handy et al., 2015; Cervero, 1996; Hong et al., 2014; Holtzclaw et al., 2002; McCormack et al., 2001; Krizek, 2003). Ewing et al. (2015) and Hong et al. (2014) found that road network density is also negatively correlated with household car ownership in urban areas. However, road density acts as a proxy for accessibility by cars to external locations in a rural area (Headicar et al., 1994). It may have a positive correlation with household car ownership in the rural area. Holtzclaw et al. (2002) also found that the impact of design is weaker than those of density and diversity on household car ownership. Destination accessibility is a built environment index at a regional level and generally includes distance to a central business district (CBD) and job accessibility (Krizek, 2003; McCormack et al., 2001). Empirical studies have confirmed that households are less likely to own cars as the distance from their residence to a CBD decreases (Miller and Ibrahim, 1998; Van Acker and Witlox, 2010). Similarly, driving mileage and the number of family vehicles are fewer if a household's residence is close to the job or business center (Ewing and Cervero, 2010; Potoglou and Kanaroglou, 2008). By contrast, the household car number increases as the distance of residence to a CBD increases (Cervero and Arrington, 2008). A significant relationship has been found also between the distance to transit and household car ownership level. For example, Potoglou and Kanaroglou (2008) found that the number of household cars is fewer if public transportation stations are set up within walking distance from residential areas. Moreover, "the number of the parking lots", "parking price", and "distance to parking lot" near residential locations also have 
impacts on the level of car ownership. Car ownership level is high if low-cost parking lots are available in a community (Guo, 2013; Tyrinopoulos and Antoniou, 2013). Therefore, Chatman (2008) suggested reducing the number of parking lots to impede the increase in household car ownership level.

\subsection{Socio-demographic factors}

Socio-demographic factors have been proven to have considerable effects on household car ownership (Li and Zhao, 2017). The main socio-demographic factors include household size, income, number of children, number of workers, parking space, and educational level (Bhat and Guo, 2007; Cao and Cao, 2014; Holtzclaw et al., 2002; Keller and Vance, 2013).

Many empirical studies have found that income is an important determinant of car ownership. High-income households may have more cars than low-income households (Potoglou and Kanaroglou, 2008). Moreover, a large household size, numerous children, and a high number of licensed drivers and workers are positively related to high car ownership level (Li and Zhao, 2017; Potoglou and Kanaroglou, 2008; Tyrinopoulos and Antoniou, 2013). Educational level is closely related to income; thus, education and income have the same effect on household car ownership (Ding et al., 2017a; Fu and Farber, 2017).

In addition, with the changes in the age structure of the Chinese society, the household structure is changing (Zhao, 2014). Together with the urbanization process, China's household hukou is also changing, which influence on Chinese households significant (Cheng and Selden, 1994). Hukou is a legal document made by the household administration organization of the public security organization to record and retain the basic information of the household population (Baidubaike, 2017a). There are two types of hukou, which are urban hukou and rural hukou in China. Urban hukou is the hukou held by people who do not have the right to distribute rural land, while the rural hukou is the opposite (Baidubaike, 2017b). Rural urbanization refers to the process of transforming agricultural population into nonagricultural population and gathering into residential areas of urban nature, and transforming rural areas into urban areas or gradually increasing urban elements in rural areas (Baidubaike, 2018). In the current situation of population mobility and rapid rural urbanization, there are three types of hukou situations in the rural areas of China. (1) For most rural residents, they hold the rural hukou and live in rural areas for most of the year. (2) There are also some people who hold the rural hukou, but living in urban areas for more than half a year in order to work in cities and towns. They normally go back to the rural area for family visiting or other social events. They become the typically separated population in urban areas, i.e. urban residents who hold rural hukou. (3) In addition, along with China's rapid urbanization in rural areas, the land of the rural residents with rural hukou was expropriated and these people were turned into urban hukou residents without rural land distribution rights in the process of rural urbanization, but their living area still does not have the city characteristics, or has not yet moved to the urban area. Therefore, they are the people who are living in rural areas with urban hukou in the course of urbanization in China. Many studies have found that residents who hold the rural hukou in urban areas have fewer cars comparing with urban hukou residents (Jiang et al., 2017; Li and Zhao, 2017).

\subsection{Perception, preference and attitude}

Relatively few studies have considered psychological determinants, such as personal attitudes and preferences (Ajzen, 1991). Steg (2005) stated that people drive occasionally not because they need to, but because they want to. Her research demonstrated that the symbol of a car is an important factor of travel mode choice among people. Van and Fuji (2006) found that attitude variables significantly impact driving and commuting intentions in Japan, China, and Vietnam, but not in
Indonesia, Thailand, and the Philippines by conducting a research on the six Asian countries. Belgiawan et al. (2014) studied the car purchase motivation of undergraduates from China, Indonesia, Japan, Lebanon, the Netherlands, Taiwan, and the USA. Their results showed that significant differences exist between developed and developing countries. Students in developed countries are unwilling to buy cars. The expectation of others seems to be an important determinant factor of purchase intention, whereas income and the symbolic significance of a car are less related to purchase intention. Another important factor influencing household car ownership is the environmental attitude. People with a concept of sustainable consumption are likely to live in a neotraditional or transit-oriented community (Cao and Cao, 2014; Cao et al., 2009; Cervero, 2007; Cervero and Arrington, 2008). Flamm (2009) found that households with high environmental awareness are willing to own few private cars and buy energy-efficient cars. Researchers also found that household car ownership is related to their residential self-selection. People will select residential locations based on their individual psychological determinants, which will affect their car purchase decisions and travel behavior (Handy et al., 2005).

In summary, one of the most significant characteristics of the study of the built environment and car ownership in China is that research areas are mainly concentrated in large cities, such as Beijing, Guangzhou, Nanjing, and Jinan (Feng et al., 2014; Jiang et al., 2017; Li and Zhao, 2017; Zhao, 2011). No existing literature has focused on rural areas.

\section{Methodology}

\subsection{Model specification}

\subsubsection{Exploratory factor analysis (EFA)}

First, EFA is used to identify important broad perceptions, preferences, and attitudes to evaluate the built environment and car ownership. EFA is a multivariate statistical analysis method that can convert measured variables to a small number of non-related comprehensive factors. These comprehensive factors reflect the main information of the original measured variables and explain the relationship between measured variables. In particular, EFA studies the condensation of a large number of measured variables into a few factors with the least information loss. The general form of the EFA model is

$X_{i}=\mu+a_{i 1} F_{i 1}+a_{i 2} F_{i 2}+\ldots+a_{i n} F_{i n}+\delta_{i}(i=1,2, \ldots, p)$,

where $X_{i}$ is a random observed variable, $F_{i}$ is a common factor, $a_{i j}(i=1$, $2, \ldots, \mathrm{p}$ ) is a factor load, and $\delta_{i}$ is a special factor part that is excluded from the common factors.

The EFA result will be used in the MNL model to investigate the effects of perception, preference and attitude on household car ownership.

\subsubsection{MNL model}

Models of car ownership are classified based on the underlying choice response mechanism, namely, ordered, e.g., ordered probit and ordered logit (ORL) models, and unordered response, e.g., logit and probit models (Potoglou and Kanaroglou, 2008). The ordered response mechanism assumes that the choice for the number of cars to own arises from a 1D latent index, which reflects the propensity of a household to own cars (Bunch, 2000). By contrast, the unordered response mechanism is based on the assumption that households associate a utility value with each car ownership level and choose the level in which utility is maximized (Potoglou and Kanaroglou, 2008). Thus, the global utility maximization framework in the unordered response mechanism adds theoretical and behavioral contexts to the study of household car ownership, whereas no clear theoretical framework exists when estimating models using the ordered response mechanism (Potoglou and Kanaroglou, 2008). Bhat and Pulugurta (1998) compared the unordered with the ordered response mechanism and concluded that MNL 
provides a better representation of the car ownership decision-making process of a household when several datasets are used. Thus, we mainly adopt the MNL model to explore the effects of the rural built environment on household car ownership. Household structure attributes, individual skills, and individual's preference and attitude factors (the result of EFA) are also inputted into the model.

This study classifies car ownership into three levels: 0,1 , and $2+$. Therefore, the utility function for the car ownership of each household can be expressed as

$U(0)=\beta_{0}{ }^{\prime} x_{i 0}+\varepsilon_{i 0}$,

$U(1)=\beta_{1}{ }^{\prime} x_{i 1}+\varepsilon_{i 1}$,

$U(2)=\beta_{2}{ }^{\prime} x_{i 2}+\varepsilon_{i 2}$,

$y_{i}=j \quad$ if $U_{i}(j)>U_{i}(q) \quad \forall q \neq j$.

The MNL component is based on the assumption that a household $i$, when faced with a finite set $\{0,1,2\}$ of alternative $j$, chooses option $j$, which provides the maximum utility $U_{i}(j) . \beta$ denotes the parameters to be estimated for the observed explanatory variables $x . \varepsilon$ is assumed to be independently and identically distributed (i.i.d) with identical extreme value distribution. The distribution function is

$F\left(\varepsilon_{j}\right)=\exp \left(-\exp \left(-\varepsilon_{j}\right)\right)$.

On the basis of this specification, the choice probabilities are

$\operatorname{Prob}(j)=\operatorname{Prob}\left(U_{i}(j)>U_{i}(q)\right)=\frac{\exp \left(\beta_{j}^{\prime} x_{i j}\right)}{\sum_{q=0}^{J} \exp \left(\beta_{q}^{\prime} x_{i q}\right)}, \forall q \neq j, j=0,1,2$,

$\sum_{j=0}^{2} \operatorname{Prob}\left(y_{i}=j\right)=1,0 \leq \operatorname{Prob}\left(y_{i}=j\right) \leq 1, j=0,1,2$.

We use the option " 0 car" as the reference option, setting the coefficient $\beta_{0}=0$.This equation is rewritten as

$$
\operatorname{Prob}\left(y_{i}=j\right)=\operatorname{Prob}\left(U_{i}(j)>U_{i}(q)\right)=\frac{1}{\exp \left(\beta_{1}{ }^{\prime} x_{i 1}\right)+\exp \left(\beta_{2}{ }^{\prime} x_{i 2}\right)+1}, j
$$$$
=0 \text {, }
$$$$
\operatorname{Prob}\left(y_{i}=j\right)=\operatorname{Prob}\left(U_{i}(j)>U_{i}(q)\right)=\frac{\exp \left(\beta_{j}^{\prime} x_{i j}\right)}{\exp \left(\beta_{1}{ }^{\prime} x_{i 1}\right)+\exp \left(\beta_{2}{ }^{\prime} x_{i 2}\right)+1}, j
$$$$
=1,2 .
$$

The relative probability of $\operatorname{Prob}\left(y_{i}=j\right)$ to $\operatorname{Prob}\left(y_{i}=0\right)$ can be expressed as

$\frac{\operatorname{Prob}\left(y_{i}=j\right)}{\operatorname{Prob}\left(y_{i}=0\right)}=\exp \left(\beta_{j}^{\prime} x_{i j}\right), j=1,2$

Thus, the calculation formula for the predicted number of cars is

$N=\operatorname{Prob}\left(y_{i}=1\right) * 1+\operatorname{Prob}\left(y_{i}=2\right) * 2$.

\subsection{Data collection and descriptive analysis}

Data were collected from Sichuan Province, China. The total rural population in Sichuan Province reached 41.96 million by the end of 2016 , and the urbanization rate was $49.12 \%$. With the increasing of a mileage of the highway, the number of cars per 100 households in rural areas increased 12.38 times compared to the number in 2010. The household car ownership, urbanization rate, and mileage of highway lines of Sichuan rural areas from 2000 to 2016 are shown in Fig. 2.

To collect the data, a rural household survey had been conducted from October 1st, 2017 to January 31st, 2018. Meanwhile, geographic information system (GIS) data were collected. Sample villages were chosen based on the following two conditions. First, local residents should be willing to participate in the questionnaire survey. Second, at least one road should be directly accessible to the sample villages, and all the roads should be paved. Finally, 7 sample villages were identified, including four traditional scattered-living villages (Da Zhuang, Shuang Yan, Xin Long, and Wu Gang) and three new concentrated-living villages (Yan Jing, Dong Xing, and Shang Teng).

Based on the literature, an initial survey was developed, and was sent to the 117 rural students who were coming from Sichuan rural areas (Fu and Farber, 2017; Handy et al., 2005; Ma and Dill, 2015). The survey includes two parts, which are the village questionnaire and household questionnaire. The village questionnaire requests the general information about the village, which could be filled in by on-site measurement and interviewing with the village chief. The household questionnaire includes questions regarding the household socio-demographic information, individual activity-travel dairy, and built environment preferences, perceptions and attitudes. Later, meetings were organized to get feedbacks. Based on these feedbacks, the questionnaire was revised and improved in order to capture the actual situation in rural Sichuan. 30 students were recruited as surveyors from the 117 rural students. They were trained uniformly before conducting the survey. To guarantee the quality of the data, pre-investigation was organized to investigate the reaction of rural residents to the survey, the length of time required to complete a questionnaire, and the type of token that can entice rural residents to participate in the survey. 10 households from two sample villages (5 each) were randomly selected to participate in the investigation. After the investigation, we found that although rural residents lack the patience to complete the questionnaire, incentives have a significant effect on encouraging rural residents to complete the questionnaire. Each household questionnaire took around $1-1.5 \mathrm{~h}$ to be finished.

Finally, 374 completed household questionnaires and 7 completed village questionnaires were collected. The sample villages are shown in Fig. 3 with the number of valid questionnaires. Comparing to the China Statistical Yearbook, the sampled household structure and vehicle ownership are more or less the same. However, the value of rural household car ownership was significantly higher than the average value in China. The significant difference was attributed to several reasons. The two main reasons are: (1) In this survey, the household number was counted as the person who was holding a rural hukou, even though the person left the village to work in a city. The cars owned by rural hukou residents who worked in cities have been included. (2) The infrastructure construction and economic development levels in these sample villages were higher than the average levels in China and Sichuan. Therefore, the randomly selected households adequately represent the sample villages. The detailed comparison is shown in Table 1.

The rural built environment differs from the urban built environment in China. Thus, we regulated the measurement scope by considering the living style of the residents from the sample villages when measuring the built environment indicators. (1) The calculation scope for the built environment indicators was a circle with a $1 \mathrm{~km}$ radius from the village center (village committee or neighborhood committee office) for Huojing and Dongxing. Although the respondents from Shangteng also exhibit a centralized living style, Shangteng is a new rural village under construction. Thus, this village demonstrates many scattered-living characteristics. (2) The administrative village boundary is the scope for calculating the built environment indicators in traditional scattered-living villages. This provision is mainly explained by the considerably varying administrative areas of traditional scatteredliving villages in Sichuan Province and the inconsistent decentralization degree. The surveyed household samples were not completed within the scope of the circle with a $1 \mathrm{~km}$ radius from the center of the administrative village.

Two approaches were mainly applied to obtain the basic data of the objective built environment considering the limited geographical information of rural areas in China. First, the researchers conducted onsite measurement using the Baidu navigation app to search and measure 


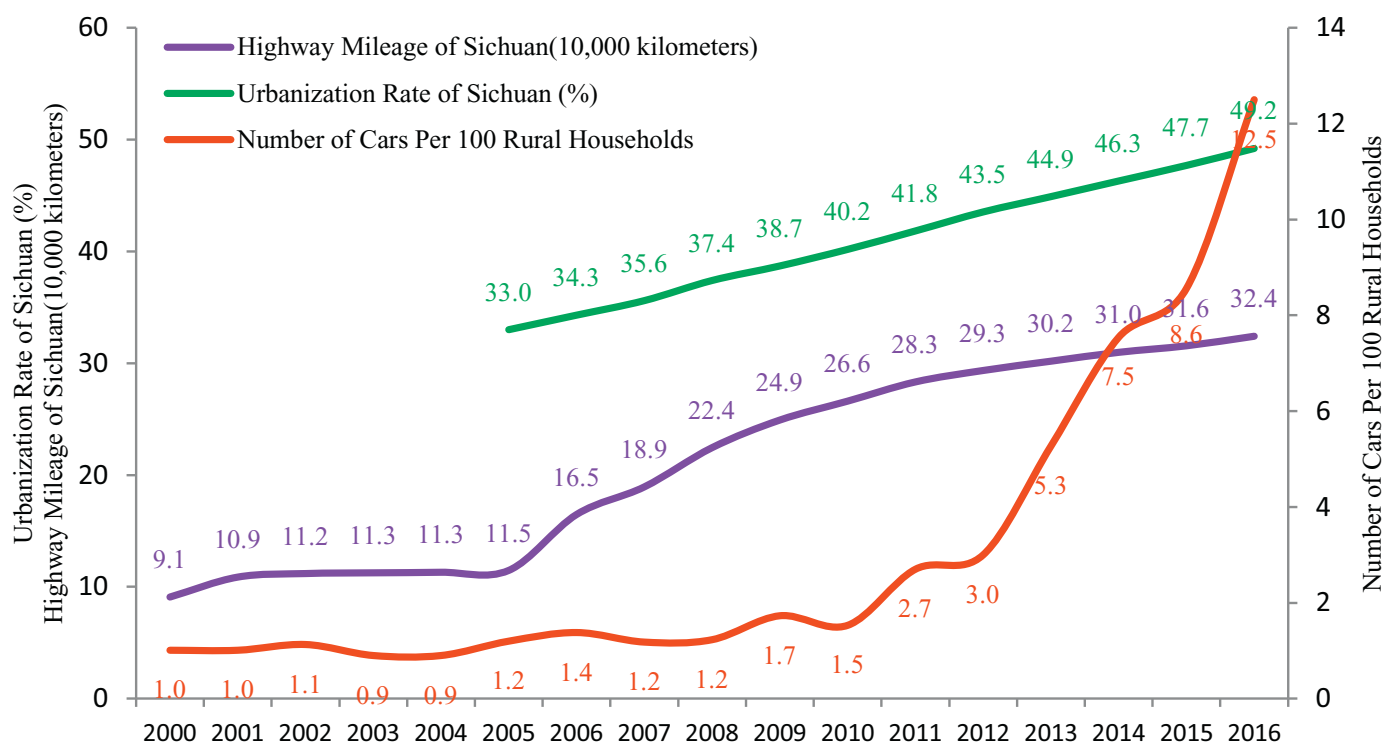

Fig. 2. Urbanization Rate, Highway Mileage and Car Ownership per 100 Rural Households of Sichuan. Sources: China Statistical Yearbook (2001-2017).

the distance to the nearest bus station, train station, bus stop, main road, market, school, health center (hospital), and the city (county) center from the village center. Table 2 presents the basic data that were measured on-site. Second, the basic data of buildings and roads were coded from Tencent Street View imagery (map.qq.com) using ArcGIS 10.2. The road and building land information from ArcGIS 10.2 is shown in Fig. 4.

\subsection{Variable specification}

We directly asked the respondents about the number of cars that their household owned during the face-to-face interview. Among the 374 sample rural households, the maximum number of cars is 3 . The dependent variable was truncated at 2 because the proportion of households with 3 cars was only $1.3 \%$. In addition, the proportions of households with 0,1 , and 2 cars were $54.3 \%, 38.8 \%$, and $5.6 \%$, respectively. The independent variables can be mainly categorized into three, namely, socio-demographic factors, preference, attitude and the built environment perception, and the objective built environment, based on the literature.

\subsubsection{Socio-demographic variables}

Socio-demographic factors will influence household car ownership decision. Therefore, this study mainly selects the variables of household structure and respondents' driving skill based on the literature, which has proven that these variables significantly impact household car ownership. The variables included in this study are as follows: (1) household size; (2) number of permanent residents, workers, members under 18, and driver's license holders; (3) household income; (4) household highest educational level; (5) number of houses and household parking spaces; (6) rural hukou; (7) number of motorcycles, ebikes, and bicycles; and (8) whether the respondents can drive a motorcycle, e-bike, and bicycle and if they have a driver's license. Finally, we categorize socio-demographic variables into two categories, which are household structure attributes and personal skills.

\subsubsection{Perception, preference and attitude variables}

To explore the effects of perception, preference and attitude on household car ownership level, 20 indicators of built environment perception and preference and 12 indicators of car ownership attitude, combined with the characteristics of rural areas, are included in the model (Cao et al., 2007; He and Thøgersen, 2017). The perception of the built environment is measured based on the respondents' judgment of the 20 built environment questions. The respondents were asked to judge the truthfulness of the built environment questions based on the current living environment using a five-point Likert-scale. 1 point indicates not true at all, whereas 5 points indicate completely true. The respondents were also asked to answer how important the built environment indicators are under the hypothetical situation of buying a house to express the preference for the built environment using a fivepoint Likert-scale. 1 point indicates not important at all, and 5 points indicate very important. To measure the attitudes towards car ownership, they were asked to assess 12 statements using a semantic differential scale ranging from 1 (completely disagree with the statement) to 5 (completely agree with the statement).

EFA was conducted to identify the important broad perceptions, preferences, and attitudes that rural residents in Sichuan used to evaluate the built environment and car ownership using SPSS 23.0. To test the suitability for factor analysis, we used the Kaiser-Meyer-Olkin (KMO) measure and Bartlett's test to explore the factorability of individual perception, preference, and attitude variables. All the KMO values are considerably above 0.6 , particularly $0.838,0.864$, and 0.679 , whereas all the $P$ values are 0.000 . The results indicate high correlations among multiple variables, thereby suggesting that the data are suitable for EFA. The items are listed in Tables 3, 4, and 5 . The variables with a factor load below 0.5 are considered insignificant and are eliminated.

The factor analysis identifies five built environment perception factors, four built environment preference factors, and four car ownership attitude factors. The identified factors respectively explain $63.69 \%, 68.81 \%$, and $66.81 \%$ of the variance, whereas the number of factors is correspondingly reduced to $25.0 \%, 20.0 \%$, and $33.33 \%$. That is, only $36.31 \%, 31.18 \%$, and $33.18 \%$ loss in information were incurred by the $75.0 \%, 80.0 \%$, and $66.67 \%$ reduction in the number of variables, respectively. Accordingly, the obscure concepts of "built environment perception", "built environment preference," and "car ownership attitude" can be better interpreted and represented. Then, the extracted components can be used in the MNL model and can effectively represent built environment perception, built environment preference, and car ownership attitude of the rural household.

\subsubsection{Objective built environment variables}

The objective built environments in rural areas of China are simpler than those in cities. Therefore, this study mainly focuses on the 


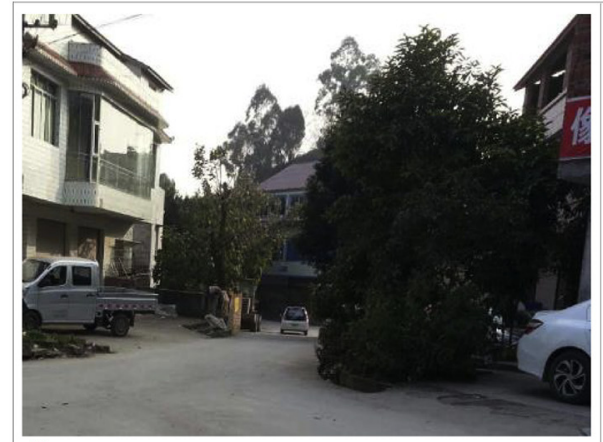

(1)Da Zhuang(57)

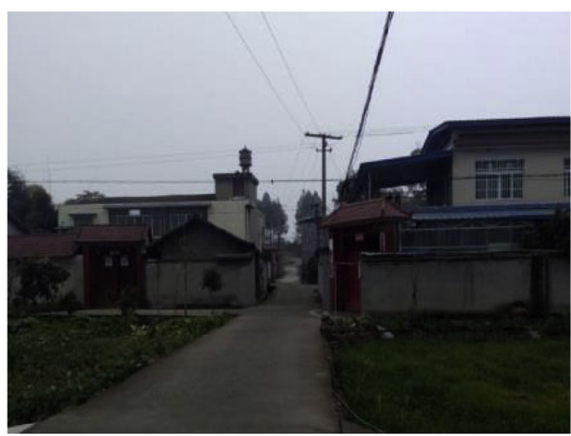

(3) Xin Long (61)

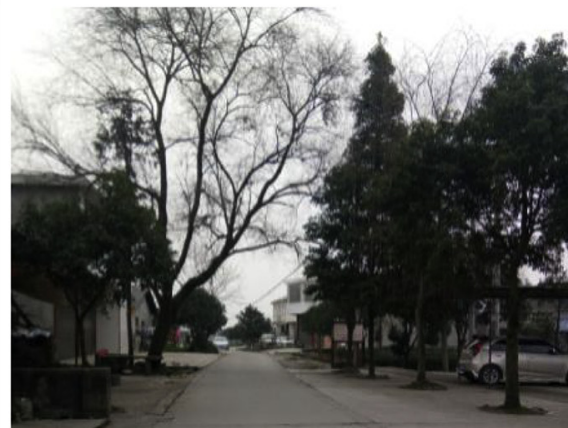

(5)Wu Gang (56)

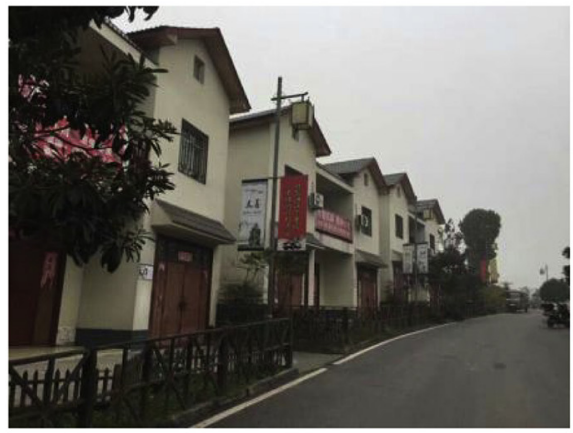

(7) Shang Teng (49)

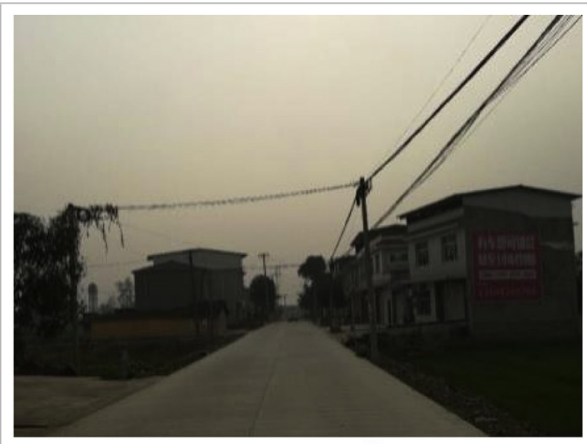

(2) Shuang $\operatorname{Yan}(53)$

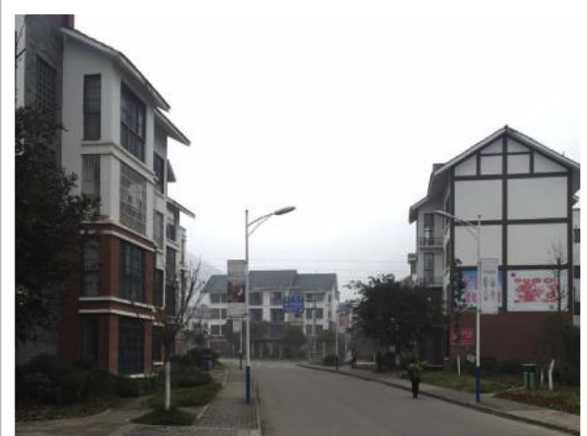

(4) Yan Jing (40)

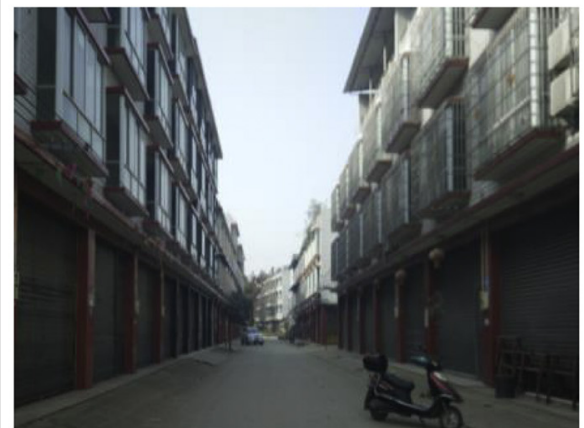

(6)Dong Xing (58)

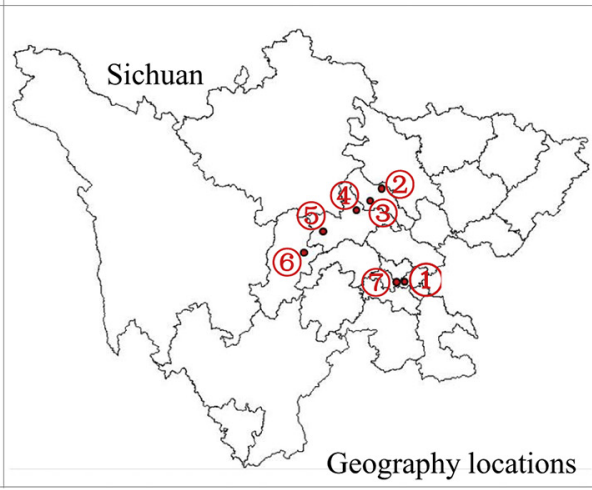

Fig. 3. Built environment, regional location and valid questionnaires.

"4Ds + 1S" built environment variables based on the on-site measurement of basic data and GIS extraction data. The "4Ds + 1S" built environment variables include design, diversity, distance to transit, destination accessibility, and living style. Due to the difficulty of obtaining accurate data on the population and households within the circle of $1 \mathrm{~km}$ radius from the central residential area, the density variables such as the population density and dwelling unit density were neglected in this study. To be more specific, these built environment variables are described as follows. Here, mu is a unit of land area used in China. In particular, 1 acre $=4046.86 \mathrm{~m}^{2}$. .

The design used in this study denotes road density and is calculated as.

Design index $=$ Total length of roads $(\mathrm{m}) /$ Total surveyed area $(\mathrm{mu})$

Land use mix is consistently used to calculate the diversity index in most related studies. However, land use in rural areas is relatively singular, and we can only read building lands using GIS technology. Thus, building density was used to calculate the diversity of rural land 
Table 1

Sample vs. population characteristics.

\begin{tabular}{|c|c|c|c|}
\hline & Household $^{\mathrm{a}}$ & Rural Sichuan $^{\mathrm{b}}$ & Rural China $^{\mathrm{b}}$ \\
\hline Total population & 1758 & 419.6 (2016:billion) & 5897.3 (2016:billion) \\
\hline Total permanent residents & 1388 & & \\
\hline Total number of households & 374 & - & - \\
\hline Average household size & 4.70 & $3.03(2015)$ & $3.88(2012)$ \\
\hline Average household permanent residents & 3.71 & - & - \\
\hline Per capita income(10 k yuan) & 1.36 & $1.13(2016)$ & $1.24(2016)$ \\
\hline Average household income( $10 \mathrm{k}$ yuan $)$ & 4.44 & - & - \\
\hline Average number of household cars & 0.54 & $0.13(2016)$ & $0.17(2016)$ \\
\hline Average number of household autobikes & 0.58 & $0.50(2016)$ & $0.65(2016)$ \\
\hline Average number of household ebikes & 0.71 & $0.27(2016)$ & $0.58(2016)$ \\
\hline Average number of household bicycles & 0.59 & $0.31(2012)$ & $0.79(2012)$ \\
\hline
\end{tabular}

a Data from face to face household survey between 29th December 2017 to 5th January 2018.

b Source: China Statistical Yearbook (2013,2016 and 2017).

Table 2

The basic data measured on-site.

\begin{tabular}{|c|c|c|c|c|c|c|c|c|}
\hline & Bus Station (KM) & $\begin{array}{l}\text { Train Station } \\
(\mathrm{KM})\end{array}$ & $\begin{array}{l}\text { Public transport station } \\
(\mathrm{KM})\end{array}$ & $\begin{array}{l}\text { Main road } \\
(\mathrm{KM})\end{array}$ & Market (KM) & School (KM) & $\begin{array}{l}\text { Health Center (hospital) } \\
(\mathrm{KM})\end{array}$ & City Center (KM) \\
\hline Dazhuang & 18.20 & 19.90 & 2.50 & 2.50 & 3.00 & 0.50 & 0.05 & 19.60 \\
\hline Wugang & 0.20 & 70.00 & 16.00 & 0.00 & 3.50 & 2.50 & 0.20 & 16.00 \\
\hline Shuangyan & 16.30 & 13.40 & 0.50 & 0.50 & 1.60 & 1.60 & 0.60 & 13.50 \\
\hline Xinlong & 13.40 & 13.40 & 1.20 & 0.80 & 0.80 & 3.00 & 4.90 & 4.90 \\
\hline Dongxing & 3.90 & 16.40 & 3.90 & 0.50 & 0.00 & 2.10 & 0.00 & 10.00 \\
\hline Shangteng & 22.40 & 24.80 & 0.69 & 0.69 & 1.50 & 1.50 & 1.60 & 14.00 \\
\hline Yanjing & 0.50 & 125.00 & 34.00 & 0.50 & 1.50 & 0.50 & 1.70 & 35.00 \\
\hline
\end{tabular}
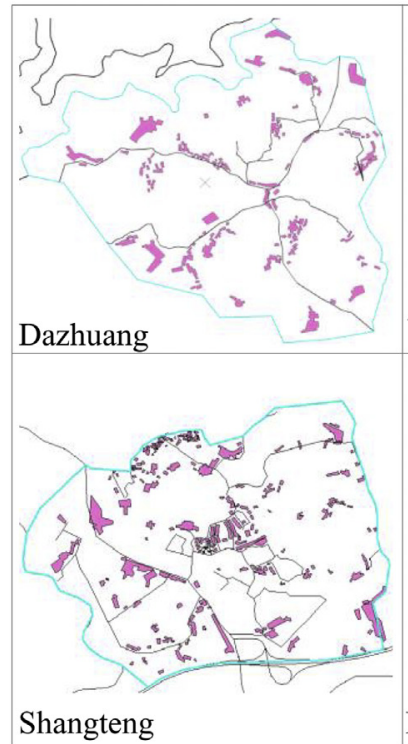

Shangteng
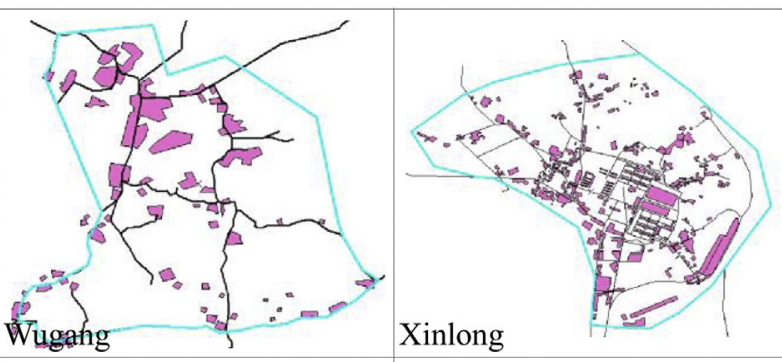

Xinlong
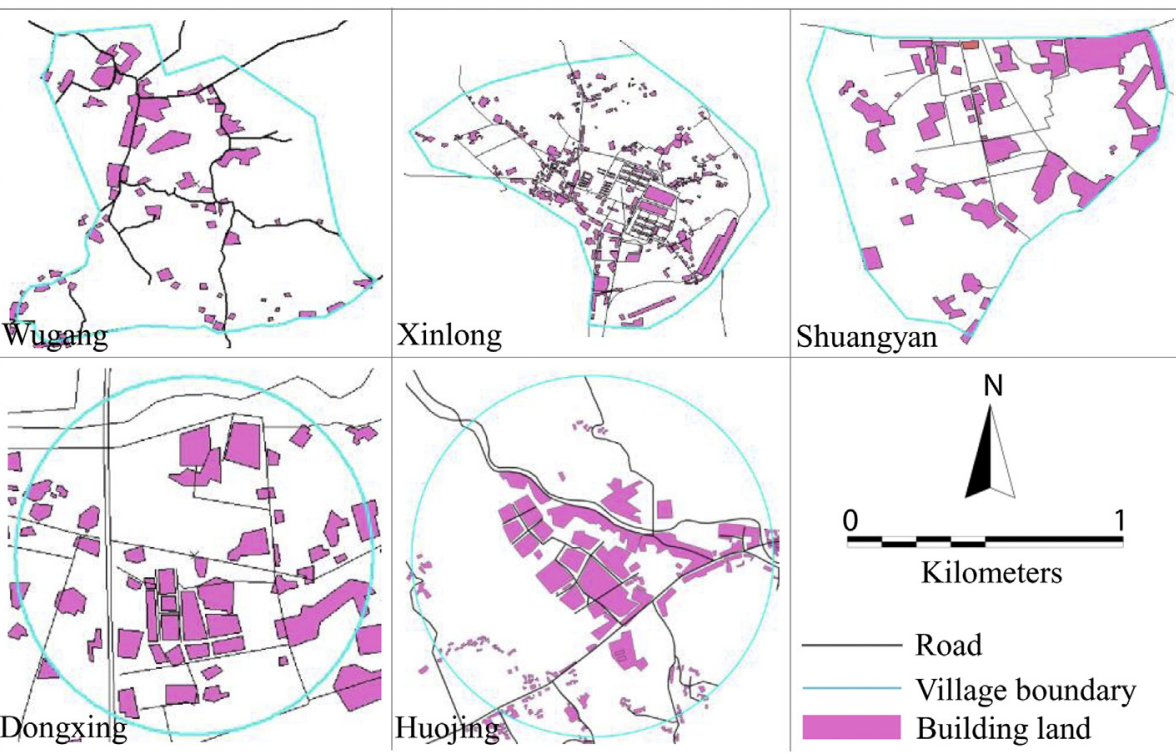

Fig. 4. Road and building land information.

use in this study.

Diversity index $=$ Building land area $\left(\mathrm{m}^{2}\right) /$ Total surveyed area $\left(\mathrm{m}^{2}\right)$

Anowar et al. (2014) used a mixed index to calculate the distance to transit. We simplified his formula to calculate the distance-to-transit mix index and the destination accessibility mix index.

Distance - to - transit mix index $=\sum_{k}\left[1 /\left(d_{k}+1\right)\right]$

where $k=1,2,3,4$, and $d_{k}$ represents the distance from the village center to the nearest bus station, train station, public transportation station, and main road.

Destination accessibility mix index $=\sum_{k}\left[1 /\left(d_{k}+1\right)\right]$ where $k=1,2,3,4$, and $d_{k}$ represents the distance from the village center to the nearest market, school, health center (hospital), and city (county) center.

As a consequence of urbanization, the living style of rural residents is gradually shifting from traditional scattered living to urbanized centralized living, and such change in living style directly influences a household's decision with regard to car ownership. Accordingly, in addition to the influences of the $\mathrm{D}$ variables, the influence of living style on rural household car ownership was investigated in this study.

\subsubsection{Variables multicollinearity}

Multicollinearity problems may cause low significance levels of various spatial variables (Ding et al., 2017a). Therefore, the 
Table 3

Built environment perception component analysis summary: Rotated Component Matrix.

\begin{tabular}{|c|c|c|c|c|c|}
\hline & \multicolumn{5}{|l|}{ Component } \\
\hline & Accessibility & Public space and services & Good neighborhood environment & Physical activity options & Few bad accidents \\
\hline Convenient to go to a market & 0.902 & & & & \\
\hline Convenient to go to school & 0.861 & & & & \\
\hline Convenient to go to city & 0.853 & & & & \\
\hline Convenient to go to transit & 0.780 & & & & \\
\hline Convenient to go to health center/hospital & 0.602 & & & & \\
\hline Spacious public courtyard & & 0.724 & & & \\
\hline Good road lighting facilities & & 0.719 & & & \\
\hline Enough parking lots & & 0.709 & & & \\
\hline Park or public open space & & 0.702 & & & \\
\hline Good maintenance service & & 0.625 & & & \\
\hline Quiet living environment & & & 0.736 & & \\
\hline It's safe to walk & & & 0.686 & & \\
\hline Good neighborhood relationship & & & 0.666 & & \\
\hline A child safe environment & & & 0.609 & & \\
\hline Good bike path & & & & 0.807 & \\
\hline Good sidewalk & & & & 0.670 & \\
\hline No traffic incident & & & & & 0.812 \\
\hline No criminal incident & & & & & 0.752 \\
\hline \multicolumn{6}{|l|}{ Summary statistics } \\
\hline Eigen value & 3.417 & 3.067 & 2.075 & 1.593 & 1.312 \\
\hline Proportion of variance explained & 18.986 & 17.040 & 11.526 & 8.848 & 7.290 \\
\hline Cumulative variance explained & 18.986 & 36.026 & 47.552 & 56.4 & 63.69 \\
\hline
\end{tabular}

Extraction Method: Principal Component Analysis. Rotation Method: Varimax with Kaiser Normalization. Rotation converged in 5 iterations. $N=374$.Factor loading below 0.5 are considered insignificant and not shown in the table. The rest of the factor analysis output can be acquired from the authors

multicollinearity of the independent variables must be examined. The variable expansion factor (VIF) was used to test for multicollinearity in this study. When VIF value is high, a particular explanatory variable is likely to be represented by a linear function model for other explanatory variables, and thus, multicollinearity problems may occur in the model (Yao et al., 2014). The VIF values of the explanatory variables are considerably below 10 (Table 6) according to our analysis, thereby indicating that no multicollinearity problem occurs.

\section{Results and discussion}

The car ownership MNL model of rural household comprises all the explanatory variables described in the previous section. The explanatory variables were individually inputted into the model following the categories of socio -demographic factors, preference and attitude, and the perceived and objective built environment with NLOGIT 5.0. This process demonstrates that each variable category contributes significantly to the model, and the log-likelihood value increases from -330.76 to -164.49 . The model result with all the variables is presented in Table 7. A total of 35 explanatory variables, excluding the specific constant variable, are adopted, and 2 parameters are estimated for each explanatory variable. Thus, the variables are $\chi^{2}$ distributed with 70 degrees of freedom, and the critical $\chi^{2}$ at the 0.01 significant level for $\mathrm{K}=70$ is 100.43 . The likelihood ratio value of this model is considerably above the critical value, thereby indicating that the null hypothesis (i.e., all parameters are zero) is rejected. In addition,

Table 4

Built environment preference component analysis summary: Rotated Component Matrix.

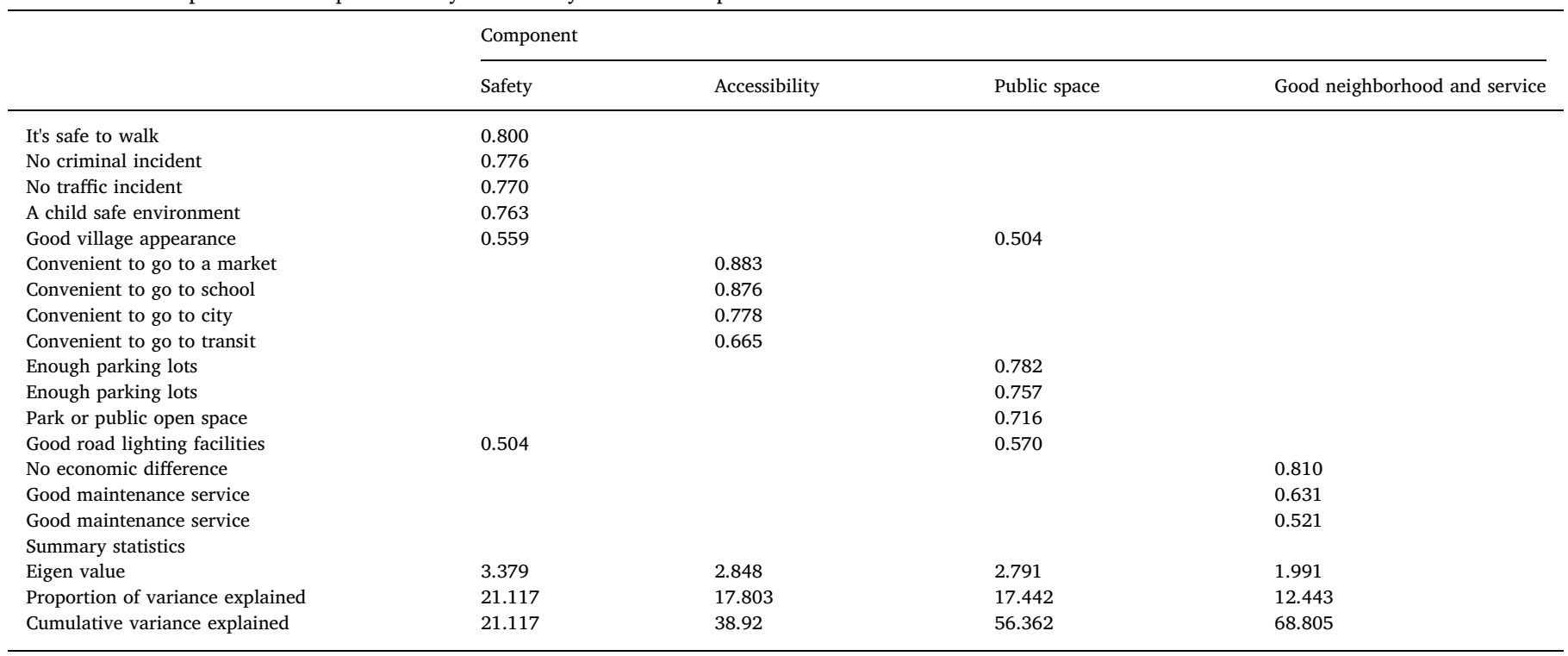

Extraction Method: Principal Component Analysis. Rotation Method: Varimax with Kaiser Normalization. Rotation converged in 6 iterations. $\mathrm{N}=374$.Factor loading below 0.5 are considered insignificant and not shown in the table. The rest of the factor analysis output can be acquired from the authors. 
Table 5

Car ownership attitude component analysis summary: Rotated Component Matrix.

\begin{tabular}{|c|c|c|c|c|}
\hline & \multicolumn{4}{|l|}{ Component } \\
\hline & Independent on car & Economy, status symbol & Cost & Fuel efficiency and road \\
\hline I am fine without a car & 0.739 & & & \\
\hline Good public transportation, no need for cars & 0.734 & & & \\
\hline Inconvenient without car & -0.677 & & & \\
\hline I need a car to do what I like to do & -0.505 & & & \\
\hline If I have (more) a car, others will pay more attention to me & & 0.829 & & \\
\hline If I have (more) a car I will be very happy & & 0.763 & & \\
\hline Car is a symbol of economic development & & 0.550 & & \\
\hline Not recommended to buy a car for pollution & & & 0.707 & \\
\hline Cars should be taxed on the amount of pollution & & & 0.687 & \\
\hline High cost of car purchase and maintenance & & & 0.575 & \\
\hline Fuel efficiency is an important factor to buy a car & & & & 0.834 \\
\hline Need to build more roads to reduce traffic congestion & & & & 0.769 \\
\hline \multicolumn{5}{|l|}{ Summary statistics } \\
\hline Eigen value & 2.562 & 1.944 & 1.225 & 1.086 \\
\hline Proportion of variance explained & 26.224 & 14.841 & 12.987 & 12.753 \\
\hline Cumulative variance explained & 26.224 & 41.065 & 54.052 & 66.805 \\
\hline
\end{tabular}

Extraction Method: Principal Component Analysis. Rotation Method: Varimax with Kaiser Normalization. Rotation converged in 5 iterations. $\mathrm{N}=374$. Factor loading below 0.5 are considered insignificant and not shown in the table. The rest of the factor analysis output can be acquired from the authors.

Table 6

Descriptive statistics summary of variables used in this study.

\begin{tabular}{|c|c|c|c|c|c|c|c|}
\hline Variables & Description & Mean & Std. dev & Min & Max & Type & VIF \\
\hline Dependent variable & & 0.54 & 0.67 & 0.00 & 3.00 & & \\
\hline Car ownership & Number of cars & & & & & Continuous & \\
\hline \multicolumn{8}{|l|}{ Explanatory variables } \\
\hline \multicolumn{8}{|l|}{ Household structure } \\
\hline Household permanent residents & Number of people & 4.70 & 1.58 & 1.00 & 12.00 & Continuous & 3.32 \\
\hline Resident population & Number of people & 3.71 & 1.68 & 0.00 & 12.00 & Continuous & 2.13 \\
\hline Population under 18 & Number of people & 0.88 & 0.85 & 0.00 & 4.00 & Continuous & 2.28 \\
\hline Household highest education & & 4.16 & 1.25 & 2.00 & 8.00 & Nominal (7 levels) & 1.38 \\
\hline Household number of workers & Number of people & 2.01 & 1.23 & 0.00 & 11.00 & Continuous & 1.55 \\
\hline Number of license holders & Number of people & 1.16 & 0.95 & 0.00 & 4.00 & Continuous & 2.05 \\
\hline Household income & Yearly, in 10000RMB & 4.44 & 3.68 & 0.00 & 40.00 & Continuous & 1.48 \\
\hline Number of housing units & Number & 1.24 & 0.70 & 0.00 & 7.00 & Continuous & 1.39 \\
\hline Household parking space & Number & 0.55 & 0.53 & 0.00 & 4.00 & Continuous & 1.39 \\
\hline Rural hukou & & 0.83 & 0.37 & 0.00 & 1.00 & Binary: 0-no/1-yes & 2.43 \\
\hline Motorcycle ownership & Number of auto bike owned & 0.58 & 0.68 & 0.00 & 6.00 & Continuous & 1.29 \\
\hline E-bike ownership & Number of e-bike owned & 0.72 & 0.65 & 0.00 & 4.00 & Continuous & 1.47 \\
\hline Bicycle ownership & Number of bicycle owned & 0.60 & 0.74 & 0.00 & 4.00 & Continuous & 1.46 \\
\hline \multicolumn{8}{|l|}{ Personal skills } \\
\hline Holing a driver's license & Whether they have a drive license & 0.25 & 0.44 & 0.00 & 1.00 & Binary: 0-no/1-yes & 1.65 \\
\hline Can ride motorcycle & Whether they can ride motorcycle & 0.39 & 0.49 & 0.00 & 1.00 & Binary: 0-no/1-yes & 1.69 \\
\hline Can ride e-bike & Whether they can ride e-bike & 0.64 & 0.48 & 0.00 & 1.00 & Binary: 0-no/1-yes & 2.43 \\
\hline Can ride bicycle & Whether they can ride bicycle & 0.71 & 0.45 & 0.00 & 1.00 & Binary: 0-no/1-yes & 2.25 \\
\hline \multicolumn{8}{|l|}{ Car ownership attitude } \\
\hline Independent on car & See Table 4 & 0.00 & 1.00 & -2.90 & 3.18 & Common factor & 1.30 \\
\hline Economy, status symbol & See Table 4 & 0.00 & 1.00 & -2.89 & 2.53 & Common factor & 1.22 \\
\hline Cost & See Table 4 & 0.00 & 1.00 & -3.19 & 3.36 & Common factor & 1.11 \\
\hline Fuel efficiency and road & See Table 4 & 0.00 & 1.00 & -3.07 & 2.56 & Common factor & 1.24 \\
\hline \multicolumn{8}{|l|}{ Built environment preference } \\
\hline Safety & See Table 3 & 0.00 & 1.00 & -4.08 & 2.38 & Common factor & 1.21 \\
\hline Accessibility & See Table 3 & 0.00 & 1.00 & -4.10 & 2.37 & Common factor & 1.27 \\
\hline Public space & See Table 3 & 0.00 & 1.00 & -3.59 & 2.64 & Common factor & 1.14 \\
\hline Good neighborhood and service & See Table 3 & 0.00 & 1.00 & -3.51 & 2.07 & Common factor & 1.16 \\
\hline \multicolumn{8}{|l|}{ Perceived Built environment } \\
\hline Accessibility & See Table 2 & 0.00 & 1.00 & -3.33 & 2.52 & Common factor & 1.46 \\
\hline Public space and services & See Table 2 & 0.00 & 1.00 & -2.91 & 2.27 & Common factor & 1.60 \\
\hline Good neighborhood and service & See Table 2 & 0.00 & 1.00 & -3.09 & 2.34 & Common factor & 1.25 \\
\hline Physical activity options & See Table 2 & 0.00 & 1.00 & -2.56 & 3.93 & Common factor & 1.19 \\
\hline Few bad accidents & See Table 2 & 0.00 & 1.00 & -2.15 & 3.23 & Common factor & 1.15 \\
\hline \multicolumn{8}{|l|}{ Objective built environment } \\
\hline Building density & See Eq. (8) & 11.81 & 5.60 & 4.76 & 19.52 & Continuous & 6.04 \\
\hline Road density & See Eq. (9) & 2.91 & 0.69 & 1.74 & 3.51 & Continuous & 2.26 \\
\hline Distance to transit mix index & See Eq. (10) & 1.70 & 1.18 & 0.67 & 4.46 & Continuous & 6.06 \\
\hline Destination accessibility & See Eq. (11) & 1.59 & 0.42 & 1.14 & 2.41 & Continuous & 3.57 \\
\hline Living style & Whether to live in concentration & 0.39 & 0.49 & 0.00 & 1.00 & Binary: 0-no/1-yes & 2.91 \\
\hline
\end{tabular}


Table 7

MNL, ORP and ORL estimated parameters of household car ownership.

\begin{tabular}{|c|c|c|c|c|c|c|c|c|c|}
\hline \multirow[t]{3}{*}{ Variables } & \multicolumn{5}{|c|}{ MNL } & \multirow{2}{*}{\multicolumn{2}{|c|}{ ORP }} & \multirow{2}{*}{\multicolumn{2}{|c|}{ ORL }} \\
\hline & \multirow[t]{2}{*}{0} & \multicolumn{2}{|l|}{1} & \multicolumn{2}{|l|}{$2+$} & & & & \\
\hline & & Beta & $\mathrm{P}$ & Beta & $\mathrm{P}$ & Beta & $\mathrm{P}$ & Beta & $\mathrm{P}$ \\
\hline Specific constants & - & -7.825 & 0.000 & -27.080 & 0.000 & -4.170 & 0.000 & -7.002 & 0.000 \\
\hline \multicolumn{10}{|l|}{ Household structure } \\
\hline Household size & - & -0.085 & 0.655 & 0.862 & 0.064 & -0.069 & 0.444 & -0.124 & 0.448 \\
\hline Resident population & - & -0.071 & 0.616 & -0.573 & 0.151 & -0.038 & 0.571 & -0.047 & 0.694 \\
\hline Population under 18 & - & 0.338 & 0.211 & 1.777 & 0.024 & 0.415 & 0.002 & 0.705 & 0.003 \\
\hline Household highest education & - & -0.267 & 0.084 & -0.670 & 0.129 & -0.087 & 0.246 & -0.171 & 0.199 \\
\hline Household number of workers & - & 0.118 & 0.468 & -0.034 & 0.950 & 0.054 & 0.482 & 0.112 & 0.419 \\
\hline Number of driver license holders & - & 1.173 & 0.000 & 2.744 & 0.000 & 0.650 & 0.000 & 1.145 & 0.000 \\
\hline Household income & - & 0.359 & 0.000 & 0.715 & 0.000 & 0.170 & 0.000 & 0.316 & 0.000 \\
\hline Number of housing units & - & -0.017 & 0.955 & 0.045 & 0.947 & 0.086 & 0.488 & 0.162 & 0.445 \\
\hline Household parking space & - & 1.109 & 0.002 & 3.119 & 0.013 & 0.607 & 0.000 & 1.018 & 0.001 \\
\hline Ruralhukou & - & 0.496 & 0.435 & 6.761 & 0.037 & 0.622 & 0.040 & 1.076 & 0.043 \\
\hline Motorcycle ownership & - & -0.573 & 0.071 & 0.351 & 0.675 & -0.001 & 0.996 & 0.010 & 0.966 \\
\hline Ebike ownership & - & 0.122 & 0.690 & -0.384 & 0.712 & 0.139 & 0.324 & 0.230 & 0.373 \\
\hline Bicycle ownership & - & -0.047 & 0.851 & -1.227 & 0.161 & -0.129 & 0.283 & -0.227 & 0.285 \\
\hline \multicolumn{10}{|l|}{ Driving skills } \\
\hline Holing a driver's license & - & 0.937 & 0.037 & 1.085 & 0.352 & 0.438 & 0.025 & 0.690 & 0.050 \\
\hline Can ride motorcycle & - & -0.299 & 0.474 & -3.133 & 0.020 & -0.381 & 0.036 & -0.628 & 0.060 \\
\hline Can ride bicycle & - & 0.875 & 0.093 & 4.852 & 0.018 & 0.770 & 0.001 & 1.326 & 0.002 \\
\hline Can ride ebike & - & -0.525 & 0.281 & -0.166 & 0.915 & -0.390 & 0.100 & -0.699 & 0.100 \\
\hline \multicolumn{10}{|l|}{ Car ownership attitude } \\
\hline Independent on car & - & -0.203 & 0.274 & -0.948 & 0.062 & -0.174 & 0.047 & -0.342 & 0.031 \\
\hline Economy, status symbol & - & 0.011 & 0.953 & -0.328 & 0.592 & -0.064 & 0.462 & -0.108 & 0.473 \\
\hline Cost & - & -0.241 & 0.162 & -0.673 & 0.255 & -0.154 & 0.074 & -0.249 & 0.104 \\
\hline Fuel efficiency and road & - & 0.083 & 0.638 & 0.137 & 0.782 & 0.055 & 0.511 & 0.143 & 0.340 \\
\hline \multicolumn{10}{|l|}{ Built environment preference } \\
\hline Safety & - & 0.139 & 0.434 & -0.413 & 0.492 & 0.014 & 0.881 & 0.010 & 0.952 \\
\hline Accessibility & - & 0.071 & 0.679 & 0.813 & 0.236 & 0.094 & 0.279 & 0.145 & 0.348 \\
\hline Public space & - & 0.031 & 0.849 & -0.271 & 0.575 & 0.014 & 0.866 & 0.039 & 0.788 \\
\hline Good neighborhood and service & - & -0.275 & 0.100 & -0.881 & 0.091 & -0.130 & 0.112 & -0.242 & 0.095 \\
\hline \multicolumn{10}{|l|}{ Perceived built environment } \\
\hline Accessibility & - & 0.053 & 0.788 & 1.889 & 0.005 & 0.217 & 0.019 & 0.381 & 0.020 \\
\hline Public space and services & - & -0.088 & 0.669 & -0.185 & 0.775 & -0.003 & 0.980 & 0.035 & 0.845 \\
\hline Good neighborhood environment & - & -0.080 & 0.648 & 0.732 & 0.220 & 0.004 & 0.963 & -0.001 & 0.995 \\
\hline Physical activity options & - & -0.011 & 0.949 & 0.229 & 0.672 & -0.060 & 0.472 & -0.100 & 0.499 \\
\hline Few bad accidents & - & 0.472 & 0.019 & 1.231 & 0.042 & 0.209 & 0.010 & 0.376 & 0.008 \\
\hline \multicolumn{10}{|l|}{ Objective built environment } \\
\hline Building density & - & 0.117 & 0.097 & 0.579 & 0.023 & 0.081 & 0.018 & 0.152 & 2.470 \\
\hline Road density & - & 0.926 & 0.013 & 1.339 & 0.191 & 0.355 & 0.038 & 0.560 & 0.071 \\
\hline Distance to transit mix index & - & 0.149 & 0.646 & -2.766 & 0.068 & -0.139 & 0.375 & -0.291 & 0.301 \\
\hline Destination accessibility & - & 0.137 & 0.849 & -1.239 & 0.571 & -0.088 & 0.792 & -0.262 & 0.663 \\
\hline Living style & - & 0.228 & 0.671 & -1.984 & 0.285 & -0.050 & 0.850 & -0.102 & 0.828 \\
\hline Number of observations & & & & 374.000 & & 374.000 & & 374.000 & \\
\hline Log-likelihood with alternate specific constants (L(C)) & & & & -330.754 & & -330.754 & & -330.754 & \\
\hline Log-likelihood model $(\mathrm{L}(\beta))$ & & & & -164.493 & & -187.461 & & -187.637 & \\
\hline Likelihood ratio $=-2[\mathrm{~L}(\mathrm{c})-\mathrm{L}(\beta)]$ & & & & 332.522 & & 286.586 & & 286.233 & \\
\hline Rho-squared( $\left.\mathrm{R}^{2}=1-[\mathrm{L}(\beta) / \mathrm{L}(\mathrm{c})]\right)$ & & & & 0.503 & & 0.433 & & 0.433 & \\
\hline Adjusted rho-squared (Adj- $\left.\mathrm{R}^{2}=1-[(\mathrm{L}(\beta)-\mathrm{M}) / \mathrm{L}(\mathrm{c})]\right)$ & & & & 0.450 & & 0.323 & & 0.327 & \\
\hline
\end{tabular}

Note: ORL represents ordered logit model, ORP represents ordered probit model.

the relatively high rho-squared $\left(R^{2}\right)$ value also indicates that the model fits well.

We specify a set of specific constants for car ownership. Specific constants for one car and two or more cars are statistically significant. In general, specific constants mainly capture unobserved information beyond all explanatory variables (Moshe and Lerman, 1985). In the car ownership model, specific constant items refer to the costs associated with car ownership, such as purchase, lease, usage, and maintenance costs (Ryan and Han, 1999). This model does not include specific cost variables because the cost information of households with cars is difficult to collect accurately. Moreover, the relationship between unobserved information, such as cost and car ownership, is reflected by specific constants. The utility of rural households with cars decreases as the number of owned cars increases if other conditions are equal. This result is consistent with the findings of other scholars (Potoglou and Kanaroglou, 2008; Ryan and Han, 1999).

Among the family structure variables, the number of household members under the age of 18 , the number of household members with driver's license, total household income, and the number of householdowned parking spaces are continuous variables. The beta values of these variables are all positive. The beta values of these variables are higher for $2+$ cars than 1 car (Table 7). This finding indicates that the households which have a higher number of household members under 18, household members with driver's license, total household income, and household-owned parking spaces increase, they are more likely to own a car and have $>1$ cars. This finding agrees with the conclusion of existing research (Choudhary and Vasudevan, 2017; He and Thøgersen, 2017; Potoglou and Kanaroglou, 2008). Interestingly, the rural hukou 
variable has a positive relationship with car ownership, and the probability of a household with rural hukou owning $>1$ cars is considerably high and statistically significant. This result contradicts the conclusion of Yang et al.'s (2017) study conducted in Jinan City, China. However, the study area of Yang et al. is different from this study which focuses on the city area. Their findings are consistent with the situation in urban areas, due to rural residents who work in urban areas tend to be indeterminate. An in-depth analysis indicates that our finding is in line with the actual conditions of rural areas in China. In the process of China's urbanization, some rural residents are urbanized. The lands of these rural residents are expropriated, and they have to rely on government subsidies to live without stable work. In addition, these rural residents face a series of problems, such as choosing a relocation area and determining the best time to transfer. Therefore, urbanized rural households in rural areas have a low utility for household-owned cars and are less likely to own more cars. Vice versa, un-urbanized rural households are more likely to own cars. With regard to household size, this variable agrees with the conclusion of Ding et al. (2016) that households which have more people are likely to own more cars. Finally, a negative correlation exists between the number of motorcycles and cars owned by a rural household. Under the existing rural built environment, rural households with motorcycles can easily reach surrounding areas. Thus, a motorcycle is a good alternative to a car.

Apart from household structure variables, driving skills of the respondents were also collected. The driving skills of the respondents involve four variables: whether they have a driver's license and whether they can ride a motorcycle, a bicycle, and an e-bike. The first three variables exhibit statistical significance. The beta values of having a driver's license and being able to ride a bicycle are positive and increase with an increase in the number of household cars. They indicate that in rural Sichuan, a complementary relationship exists between bicycling and driving. Moreover, as the number of household cars increases, the beta values increase which indicates that there is a stronger relationship between whether they can ride/drive, and the households owning more than one cars. By contrast, the beta value of being able to ride a motorcycle is negative and decreases significantly with an increase in car ownership. It indicates that households that use motorcycles are less likely to own cars. As mentioned above that the motorcycle is a good alternative to a car for the rural area of Sichuan. For this type of rural residents or families, either riding a motorcycle or owning a car may satisfy their basic needs for traveling. This finding is consistent with the finding for the number of vehicles in the previous section.

For car ownership attitudes, only one common factor variable has a significant relationship with household car ownership. The significant finding is that the less dependent rural residents are on cars, the less likely they are to own cars. This finding is consistent with that of Cao et al. (2007), i.e., the more people rely on cars, the more likely they are to own cars. Although the variable of a private car as a status and economic symbol is insignificant, the beta sign is extremely interesting. People who own a car as a status and economic symbol are more likely to own only one car than two or more cars. This finding disagrees with the result of Yang et al. (2017) in their study conducted on a Chinese city. These contrasting findings exhibit the difference in the influence of car ownership attitudes on car ownership between rural and urban households in China. Rural households own one car to satisfy the psychological demand of cars as a status and economic symbol. Owning more cars will have a negative impact because of the increasing costs. However, Chinese urban residents may have travel, work, and other needs. Such households tend to own two or more cars.

For the relationship between the preferences for the built environment of rural residents and the car ownership, only one of the four common factors has a significant negative relationship with the household car ownership, i.e., a good neighborhood and service. Here, such relationship indicates that no difference exists in terms of economic conditions among neighbors. Neighbors frequently chat with one another, and the maintenance service for public facilities is excellent.
This finding complies with our expectation. People who are living in a good neighborhood service area tend to have a lower possibility to own a car or more than one cars. Their scope of activities might be limited within the village area.

To compare relationships between the objective built environments and household car ownership with the perceived built environment and household car ownership, we discuss these two categories together. The beta values of the objective built environment for accessibility to public institutions and public transport is completely opposite to that of the perceived built environment for rural households who have more than one cars. The result shows that the objective access to public transport and public institutions has a negative relationship with the household car ownership of $2+$, which indicates that the more accessible the built environment, the less likely are rural households to own more than one cars. This finding is consistent with the findings of Ding et al. (2017a). The positive relationship between the perceived built environment of rural residents and household car ownership is logical as well. This finding is due to the rapid urbanization of rural Sichuan and the rapid development of rural infrastructure (Figs. 1 and 2). In the past, traveling was inconvenient for rural residents. In the perceived built environment, however, rural residents experience a fundamental change brought about by being able to drive a car. Therefore, perceived accessibility positively related with the option of owning two or more cars by rural households. The perceived built environment of few bad accidents such as traffic accident and crime incident near homes has a positive relationship with household car ownership. In addition, the relationship is stronger for the households which have more than one cars, which is consistent with our expectation. The actual building density positively influences the car ownership of rural households. This finding is contrary to the results of the existing literature on cities. The general belief is as follows: the higher the building density in a city, the more conducive to physical activities for residents, and the lower the level of household car ownership (Bhat and Guo, 2007; Ding et al., 2017a; Li and Zhao, 2017; Zegras, 2010). However, for the rural areas of Sichuan, the building density is much lower than an urban area. The higher building density in rural areas at this moment reflects the better living conditions with more activity locations. Therefore, it is logical to have a positive relationship between building density and household car ownership after controlling the household income variable. Road density has a significantly positive relationship with owning of one car. It means that rural residents are more likely to hold one car in a higher road density area. The result is logical since, in rural areas of Sichuan, the density of the roads is acting as a proxy for accessibility by cars to external locations. For a higher road density area, people are more likely to connect their cars with external locations and expand their activities. This finding is consistent with the conclusion of Headicar et al. (1994).

Overall, socio-demographic factors have the most significant relationship with the car ownership of rural households based on the estimation of the standardized parameters of various variables, which agree with the finding of the existing literature (Cullinane, 2003). Compared with perception, preference and attitude, the characteristics of the built environment (including perceived and objective built environments) have more significant beta values. This result is contrary to the findings of Cao et al. (2007). Such contradiction could be explained by the evident changes in the built environment during the rapid development of rural areas.

Finally, we use the same variables to estimate the ORP and ORL models. The results are presented in Table 7 as well. Most parameters have the same signs. MNL is the best model according to the likelihood ratio and Rho-squared. Therefore, in this study, we mainly focused on the results interpretation of the MNL model.

\section{Conclusion}

Rapid rural urbanization and new rural construction have brought 
about rapid changes in rural China, along with a dramatic increase in the energy consumption of rural residents. One of the key factors that affect the travel behavior of rural residents and air pollution is the rapid increase in car ownership of rural households. This study uses survey data from Sichuan rural households and GIS data for the first time to analyze the relationship between the built environment and rural household car ownership after controlling for individual's preference and attitude, and socio-demographic factors using the MNL model.

Household characteristics, such as the number of members under the age of 18 , the number of members with driver's license, total household income, the number of household-owned parking spaces, and household size significantly and positively affect household car ownership. This finding is consistent with the conclusions of the existing research. Rural hukou has a significant positive impact on household car ownership, which is contrary to the research findings in the urban context but is in line with the actual situation in rural China. The individual driving skills of the respondents significantly affect household car ownership. Driving and cycling skills positively influence household car ownership, whereas knowing how to ride a motorcycle has negative impacts on household car ownership. In addition, individual's preference and attitude also impact the car ownership of rural households to a certain extent. Individuals who do not rely on private cars and living in a good neighborhood service area are less likely owning a car or more than one cars. This finding is consistent with existing research findings.

The built environment (including perceived and objective built environment) has a significant relationship with the car ownership of rural households. The perceived build environment with few bad accidents such as no traffic accidents and crime incidents near homes positively affects household car ownership. There is a significant positive relationship between perceived accessibility and household car ownership. It might indicate that being able to travel by car considerably impacts the convenience perception of rural residents. The relationship between objective accessibility and household car ownership of $2+$ is consistent with the literature, which confirms that the more accessible the built environment, the less likely are rural households to own more than one cars. In addition, there is a positive relationship between objective building density and household car ownership. The similar relationship has been found out for road density with one car ownership as well. In Sichuan rural areas, building density and road density can represent the development level of infrastructure to a certain extent. Although rural areas are urbanizing rapidly, rural built environment indicators still lag behind their counterparts in cities. For example, the average building density of the 20 districts in Jinan City is 0.407 (Yang, 2013), whereas the average building density of the sample villages selected in this study is only 0.119. Infrastructure will be continuously improved with an increase in road density and building density in rural areas. Directing rural residents to own as few cars as possible is highly significant to rural development.

\section{Acknowledgments}

The Fundamental Research Funds for the Central Universities (2012017yjsy215). The Natural Science Key Project from Sichuan Provincial Department of Education (18ZA0048) the Fundamental Philosophy and Social Science Research Fund for Chengdu University of Technology (YJ2017-NS011). The Research on BIM Technology Resource Sharing Platform Construction and Cooperation Mechanism (CHJK\{2017\}119). Development Research Center of Oil and Gas, Sichuan (CYQK-SKB17-04).

\section{References}

Aditjandra, P.T., Cao, X.Y., Mulley, C., 2016. Exploring changes in public transport use and walking following residential relocation: A British case study. J. Transp. Land Use 9, 77-95.
Ajzen, I., 1991. The Theory Of Planned Behavior. Organ Behav. Hum. Dec. 50, 179-211. Anowar, S., Yasmin, S., Eluru, N., Miranda-Moreno, L.F., 2014. Analyzing car ownership in Quebec City: a comparison of traditional and latent class ordered and unordered models. Transportation 41, 1013-1039.

Baidubaike, 2017a. Hukou. https://baike.baidu.com/item/\%E6\%88\%B7\%E5\%8F\%A3/ 593947? $\mathrm{fr}=$ aladdin, Accessed date: 14 August 2018.

Baidubaike, 2017b. Hukou.

Baidubaike, 2018. Rural urbanization.

Belgiawan, P.F., Schmocker, J.D., Abou-Zeid, M., Walker, J., Lee, T.C., Ettema, D.F., Fujii, S., 2014. Car ownership motivations among undergraduate students in China, Indonesia, Japan, Lebanon, Netherlands, Taiwan, and USA. Transportation 41, 1227-1244.

Bhat, C.R., Guo, J.Y., 2007. A comprehensive analysis of built environment characteristics on household residential choice and auto ownership levels. Transp. Res. B Methodol. 41, 506-526.

Buehler, R., Pucher, J., Gerike, R., Gotschi, T., 2017. Reducing car dependence in the heart of Europe: lessons from Germany, Austria, and Switzerland. Transp. Rev. 37, 4-28.

Bunch, D.S., 2000. Automobile demand and type choice. Handbook of transport modelling 463. pp. 479.

Cao, J.S., Cao, X.S., 2014. The Impacts of LRT, Neighbourhood Characteristics, and Selfselection on Auto Ownership: Evidence from Minneapolis-St. Paul. Urban Stud. 51, 2068-2087.

Cao, X., Mokhtarian, P.I., Handy, S.I., 2007. Cross-sectional and quasi-panel explorations of connection between the built environment and auto ownership. Environ Plan A 39, $830-847$.

Cao, X.Y., Mokhtarian, P.L., Handy, S.L., 2009. The relationship between the built environment and nonwork travel: A case study of Northern California. Transport Res. aPol 43, 548-559.

Cervero, R., 1996. Mixed land-uses and commuting: Evidence from the American housing survey. Transport Res. a-Pol 30, 361-377.

Cervero, R., 2007. Transit-oriented development's ridership bonus: a product of self-selection and public policies. Environ Plan A 39, 2068-2085.

Cervero, Robert, Arrington, G.B., 2008. Vehicle Trip Reduction Impacts of TransitOriented Housing. J. Public Transp. 11 (3), 1-17.

Chatman, D.G., 2008. Deconstructing development density: Quality, quantity and price effects on household non-work travel. Transport Res. a-Pol 42, 1008-1030.

Cheng, T.J., Selden, M., 1994. The Origins And Social-Consequences Of China Hukou System. China Quart. 644-668.

Choudhary, R., Vasudevan, V., 2017. Study of vehicle ownership for urban and rural households in India. J. Transp. Geogr. 58, 52-58.

Cullinane, S., 2003. Hong Kong's low car dependence: lessons and prospects. J. Transp. Geogr. 11, 25-35.

Ding, C., Wang, Y., Tang, T., Mishra, S., Liu, C., 2016. Joint analysis of the spatial impacts of built environment on car ownership and travel mode choice. Transp. Res. Part D: Transp. Environ. 60, 28-40.

Ding, C., Wang, D., Liu, C., Zhang, Y., Yang, J., 2017a. Exploring the influence of built environment on travel mode choice considering the mediating effects of car ownership and travel distance. Transp. Res. A Policy Pract. 100, 65-80.

Ding, C., Wang, D.G., Liu, C., Zhang, Y., Yang, J.W., 2017b. Exploring the influence of built environment on travel mode choice considering the mediating effects of car ownership and travel distance. Transport Res. a-Pol 100, 65-80.

Ewing, R., Cervero, R., 2001. Travel and the built environment - A synthesis. Land Dev. Public Involv. Transp. 87-114.

Ewing, R., Cervero, R., 2010. Travel and the Built Environment. J. Am. Plan. Assoc. 76, 265-294.

Ewing, R., Handy, S., 2009. Measuring the Unmeasurable: Urban Design Qualities Related to Walkability. J. Urban Des. 14, 65-84.

Ewing, R., Tian, G., Goates, J.P., Zhang, M., Greenwald, M.J., Joyce, A., Kircher, J., Greene, W., 2015. Varying influences of the built environment on household travel in 15 diverse regions of the United States. Urban Stud. 52, 2330-2348.

Feng, J.X., Dijst, M., Wissink, B., Prillwitz, J., 2014. Understanding Mode Choice in the Chinese Context: The Case of Nanjing Metropolitan Area. Tijdschr Econ Soc Ge 105, 315-330.

Flamm, B., 2009. The impacts of environmental knowledge and attitudes on vehicle ownership and use. Transp. Res. D-Tr E 14, 272-279.

Fu, L., Farber, S., 2017. Bicycling frequency: A study of preferences and travel behavior in Salt Lake City, Utah. Transp. Res. A Policy Pract. 101, 30-50.

Guo, Z., 2013. Does residential parking supply affect household car ownership? The case of New York City. J. Transp. Geogr. 26, 18-28.

Handy, S., Cao, X., Mokhtarian, P., 2005. Correlation or causality between the built environment and travel behavior? Evidence from Northern California. Transp. Res. Part D: Transp. Environ. 10, 427-444.

He, S.Y., Thøgersen, J., 2017. The impact of attitudes and perceptions on travel mode choice and car ownership in a Chinese megacity: The case of Guangzhou. Res. Transp. Econ. 62, 57-67.

Headicar, P., Curtis, C., Education, P., Research Services, L., 1994. Residential Development And Car-Based Travel: Does Location Make a Difference. pp. 117-130.

Holtzclaw, J., Clear, R., Dittmar, H., Goldstein, D., Haas, P., 2002. Location efficiency: Neighborhood and socioeconomic characteristics determine auto ownership and use Studies in Chicago, Los Angeles and San Francisco. Transp. Plann. Technol. 25, 1-27.

Hong, J.H., Shen, Q., Zhang, L., 2014. How do built-environment factors affect travel behavior? A spatial analysis at different geographic scales. Transportation 41, 419-440.

Keller, R., Vance, C., 2013. Landscape pattern and car use: Linking household data with satellite imagery. J. Transp. Geogr. 33, 250-257. 
Krizek, K.J., 2003. Residential relocation and changes in urban travel - Does neighborhood-scale urban form matter? J. Am. Plan. Assoc. 69, 265-281.

Li, S., Zhao, P., 2017. Exploring car ownership and car use in neighborhoods near metro stations in Beijing: Does the neighborhood built environment matter? Transp. Res. Part D: Transp. Environ. 56, 1-17.

Ma, L., Dill, J., 2015. Associations between the objective and perceived built environment and bicycling for transportation. J. Transp. Health 2, 248-255.

McCormack, E., Rutherford, G.S., Wilkinson, M.G., 2001. Travel impacts of mixed land use neighborhoods in Seattle, Washington. Land Dev. Public Involv. Transp. 25-32.

Miller, E.J., Ibrahim, A., 1998. Urban form and vehicular travel - Some empirical findings. Land Use Transp. Plann. Prog. Appl. 18-27.

Moshe, B.-A., Lerman, S., 1985. Discrete Choice Analysis: Theory and Application to Travel Demand. Massachusetts Institute of Technology, Massachusetts.

National Bureau of Statistics, 1986-2017. China Statistical Yearbook.

National Bureau of Statistics, 2017. China Statistical Yearbook.

Pan, H.X., Shen, Q., Zhang, M., 2009. Influence of Urban Form on Travel Behaviour in Four Neighbourhoods of Shanghai. Urban Stud. 46, 275-294.

Potoglou, D., Kanaroglou, P.S., 2008. Modelling car ownership in urban areas: a case study of Hamilton, Canada. J. Transp. Geogr. 16, 42-54.

Protection, M., 2016. Annu. Rep. of Automobile Air Pollution in China.

Pucher, J., Peng, Z.R., Mittal, N., Zhu, Y., Korattyswaroopam, N., 2007. Urban transport trends and policies in China and India: Impacts of rapid economic growth. Transp. Rev. 27, 379-410.

Ryan, J., Han, G., 1999. Vehicle-ownership model using family structure and accessibility application to Honolulu, Hawaii. Transp. Res. Rec. 1-10.

Salon, D., 2015. Heterogeneity in the relationship between the built environment and driving: Focus on neighborhood type and travel purpose. Res. Transp. Econ. 52, 34-45.

Steg, L., 2005. Car use: lust and must. Instrumental, symbolic and affective motives for car use. Transp. Res. a-Pol 39, 147-162.
Tyrinopoulos, Y., Antoniou, C., 2013. Factors affecting modal choice in urban mobility. Eur. Transp. Res. Rev. 5, 27-39.

Van Acker, V., Witlox, F., 2010. Car ownership as a mediating variable in car travel behaviour research using a structural equation modelling approach to identify its dual relationship. J. Transp. Geogr. 18, 65-74.

Van, H.T., Fuji, S., 2006. A Cross Asian Country Analysis In Attitudes toward Car And Public Transport. In: Transportation Studies: Sustainable Transportation, Proceedings Of the 11th International Conference Of Hong Kong Society for Transportation Studies, pp. 803.

Vance, C., Hedel, R., 2007. The impact of urban form on automobile travel: disentangling causation from correlation. Transportation 34, 575-588.

Wang, D., Zhou, M., 2017. The built environment and travel behavior in urban China: A literature review. Transp. Res. Part D: Transp. Environ. 52, 574-585.

Wang, D., Chai, Y., Li, F., 2011. Built environment diversities and activity-travel behaviour variations in Beijing, China. J. Transp. Geogr. 19, 1173-1186.

Yang, J.W., 2010. Spatial and Social Characteristics of Urban Transportation in Beijing. Transp. Res. Rec. 59-67.

Yang, Y., 2013. Research on Neighborhood Built Environment and Household Travel Energy Consumption in Jinan. Ph.D. Thesis. Tsinghua University. Beijing, China.

Yang, J., Gu, P., Chen, Y., He, D., Mao, Q., 2017. Influence of land use and street characteristics on car ownership and use: Evidence from Jinan, China. Transp. Res. Part D: Transp. Environ. 52, 518-534.

Yao, B., Hu, P., Lu, X., Gao, J., Zhang, M., 2014. Transit network design based on travel time reliability. Transp. Res. Part C 43, 233-248.

Zegras, C., 2010. The Built Environment and Motor Vehicle Ownership and Use: Evidence from Santiago de Chile. Urban Stud. 47, 1793-1817.

Zhao, P., 2011. Car use, commuting and urban form in a rapidly growing city: evidence from Beijing. Transp. Plan. Technol. 34, 509-527.

Zhao, P.J., 2014. Private motorised urban mobility in China's large cities: the social causes of change and an agenda for future research. J. Transp. Geogr. 40, 53-63. 